\title{
How to pay the price for carbon
}

\author{
It is increasingly clear that achieving the Paris Agreement goal of limiting warming to well below $2{ }^{\circ} \mathrm{C}$ will require \\ radical decarbonization, the prospects of which have become closely tied to carbon pricing.
}

conomists generally agree that some form of carbon pricing is an essential component of climate policy. However, there is no consensus on the price, the appropriate instruments or to whom carbon prices should apply. The immediacy of the carbon pricing question was apparent at the 6th World Congress of Environmental and Resource Economics, held the last week of June. Although environmental economics stretches beyond the issue of climate change, of the seven keynote lectures and plenary speeches, four dealt with some aspect of climate economics, including a plenary address by Meredith Fowlie titled 'Carbon Pricing in the Real World' (https://go.nature.com/2L4r8yb). Many more sessions discussed the optimal design of a carbon tax in the United States, reform of the EU emissions trading scheme, how to design pricing instruments in the face of uncertainty and the challenges of implementation. Coming to terms with the range of possible policy instruments, the variation in prices and appropriate coverage is of paramount importance.

To this end, the Carbon Pricing Leadership Coalition (https://www. carbonpricingleadership.org), launched on the opening day of COP 21 in Paris with the backing of the World Bank Group, plays a role in supporting the development and implementation of carbon pollution pricing systems around the globe. As of 2017, there were 42 national and 25 subnational jurisdictions implementing some combination of emissions trading schemes and carbon taxes ${ }^{1}$. However, bolder and broader action on carbon pricing is needed. The CPLC's Report of the High-Level Commission on Carbon Prices concludes that carbon prices are an indispensable way to reduce emissions, but all countries will need to implement a package of climate policies if the Paris Agreement target is to be met ${ }^{2}$.

Support for carbon pricing across the political spectrum has been slow to manifest, but this may be changing in the United States - despite what seems like a continuous flow of disheartening

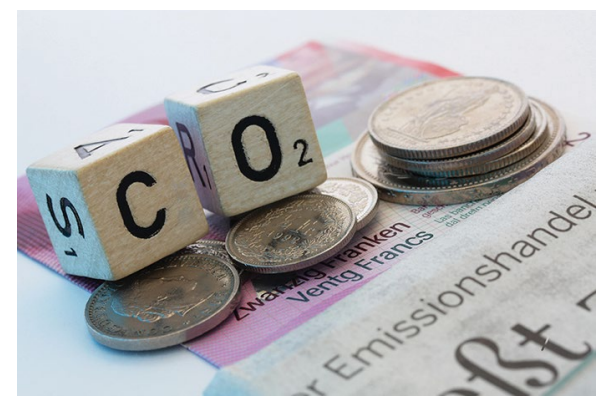

Credit: Hans Bechheim/Alamy Stock Photo

environmental news from the current administration. The Climate Leadership Council (CLC, https://www.clcouncil.org), launched in June 2017, lists among its founding members a veritable who's who of the global business and political elite. The group has attempted to make a 'Conservative' case for a carbon taxand-dividend plan. Such a policy faces substantial hurdles, because the plan asks for a carbon tax, coupled with redistribution, in return for environmental deregulation. Both ends of this proposal may be non-starters for the Right and Left, respectively. Environmental groups have cast this trade-off - and the CLC itself as a disguised effort to unravel decades of regulatory gains on clean air and water ${ }^{3}$.

Nevertheless, the CLC's carbon pricing plan (also known as the Baker-Schultz Carbon Dividends Plan) is now supported by a new lobbying group: Americans for Carbon Dividends (https://www.afcd.org), led by former Senate Republican leader Trent Lott and former Senate Democrat John Breaux ${ }^{4}$. Although the group is technically bipartisan, Breaux, during his tenure in Congress, was routinely ranked among the most conservative Democrats. In reality, the two groups represent a something of a public shift in support for a national climate policy among some US right-leaning groups, including a large group of College Republicans (https://www.s4cd.org).
The CLC's plan is distinctly political. In this issue, a Perspective by Klenert and colleagues considers research explaining why revenue recycling - such as the dividend portion of the CLC plan - can lead to public acceptance of carbon pricing. The public's willingness to pay a price for carbon is a function of political, economic and cultural beliefs. Knowledge of these constraints can facilitate the design of politically acceptable carbon-pricing instruments. For example, Canada, France and Sweden have markedly different revenue transfer schemes. Most importantly, Klenert et al. demonstrate that revenue recycling schemes can be designed to address distributional, efficiency and competitiveness concerns, and even public skepticism about the benefits of higher carbon prices.

The academic literature has made considerable strides in understanding the costs and benefits of carbon pricing. The real world, however, has moved at a much slower pace. In the United States, recent changes to the Environmental Protection Agency's Scientific Advisory Board included the disbanding of the Expert Advisory Committee on Environmental Economics ${ }^{4,5}$. A majority of emissions remains outside of carbon pricing schemes, and implementing effective climate policy remains a challenge. For carbon pricing to be effective, a variety of best practices must be adopted.

Published online: 30 July 2018 https://doi.org/10.1038/s41558-018-0256-0

References

1. State and Trends of Carbon Pricing 2017 (World Bank, Ecofys \& Vivid Economics, 2017).

2. Report of the High-Level Commission on Carbon Prices (Carbon Pricing Leadership Coalition, 2017).

3. Wald, E. R. The climate leadership council's devious plan to distract American carbon consumers. Forbes (20 June 2017); https://go.nature.com/2Ju4nxV

4. Lott, T. \& Breaux, J. Here's how to break the impasse on climate. The New York Times (20 June 2018); https://go.nature. com/2KYu9A5

5. Halpern, M. The EPA science advisory board is being compromised. Here's why that matters. Union of Concerned Scientists (30 October 2017); https://go.nature.com/2NkBTZP 